\title{
Effects of glutamic acid shelled PAMAM dendrimers on the crystallization of calcium phosphate in diffusion systems
}

\author{
Liben Xie • Lei Wang • Xinru Jia • Guichao Kuang • \\ Sheng Yang $\cdot$ Hailan Feng
}

Received: 15 December 2009/Revised: 6 July 2010/Accepted: 8 July 2010/

Published online: 22 July 2010

(C) The Author(s) 2010. This article is published with open access at Springerlink.com

\begin{abstract}
Second generation poly(amidoamine) (PAMAM) dendrimers were synthesized and peripherally modified with glutamic acid (PAMAM-MG) as a shell. The effect of the dendrimers on the crystallization of different calcium phosphate compounds was investigated in both double and one way diffusion systems. It was found that the crystals of calcium phosphate showed tape-like morphology in the presence of PAMAM-MG, and the crystals' thickness and width decreased compared to those grown without dendritic molecules. Such a result might be due to the interaction of electric charges between dendritic molecules and octacalcium phosphate $\left(\mathrm{Ca}_{8} \mathrm{H}_{2}\left(\mathrm{PO}_{4}\right)_{6} \cdot 5 \mathrm{H}_{2} \mathrm{O}\right.$, OCP), which led to the adsorption of PAMAM-MG in the 100 and 010 surfaces of OCP. Moreover, PAMAM-MG showed an affinity for gelatin, and it could cause the formation of amorphous calcium phosphate $\left(\mathrm{Ca}_{9}\left(\mathrm{PO}_{4}\right)_{6} \cdot n \mathrm{H}_{2} \mathrm{O}, \mathrm{ACP}\right)$ at a concentration of $5 \mathrm{mg} / \mathrm{mL}$ of PAMAM-MG. These results suggest that PAMAM-MG could be used for regulating the morphology of OCP and changing the composition of minerals in gels.
\end{abstract}

Keywords Poly(amidoamine) - Double diffusion system · Crystal morphology · Affinity $\cdot$ Adsorption mechanism

L. Xie $\cdot$ L. Wang $\cdot$ S. Yang $\cdot$ H. Feng $(\bowtie)$

Department of Prosthodontics, Peking University School and Hospital of Stomatology,

Beijing 100081, China

e-mail: fenghl@ht.rol.cn.net

X. Jia $(\bowtie) \cdot$ G. Kuang

Department of Polymer Science and Engineering, College of Chemistry and Molecular Engineering, Peking University, Beijing 100871, China

e-mail: xrjia@pku.edu.cn 


\section{Introduction}

Extracellular noncollagenous proteins play important roles in the formation of bone and dentin by regulating mineral nucleation and mineral crystal growth. Such actions are believed to be related to their functional groups, including $\mathrm{SO}_{4}{ }^{2-}, \mathrm{PO}_{4}{ }^{3-}$ and $\mathrm{COO}^{-}[1,2]$. Some natural amino acids, including sodium salts of poly(aspartic acid) and poly(glutamic acid), have been reported to influence both calcium carbonate and calcium phosphate crystal growth [3-7]. In contrast to less branched polypeptides, dendritic molecules, for example, poly(amidoamine) (PAMAM) dendrimers have attracted increasing interest for the regulation of inorganic compounds [8,9] due to their controllable sizes, well-defined structures, and multiple functional groups. Such molecules have a disk-like shape in their early generations and a more rigid and sphere-like one in later generations. They are proposed as mimics of anionic micelles or artificial proteins [10, 11]. Zhang et al. reported that the morphology and size of $\mathrm{BaWO}_{4}$ crystals were affected by both the generation number and the concentration of PAMAM dendrimers with carboxylate groups during hydrothermal treatment which included direct mixing of reacting solutions followed by heat treatment [9]. Naka et al. reported that PAMAM could regulate the morphologies of $\mathrm{CaCO}_{3}$ crystals which formed spherical vaterite in the presence of PAMAM and rhombohedral calcite without PAMAM [12]. They also showed that PAMAM G4.5 dendrimers induced vaterite formation more effectively than earlier generations by the double-jet method [13], and the vaterite crystals predominated when the $(-\mathrm{COONa}) /\left(\mathrm{Ca}^{2+}\right)$ concentration ratio was higher than 0.053 [13]. Moreover, PAMAM G3.5 was used to prepare a $\mathrm{CaCO}_{3} /$ poly(ethylenimine) composite film, whereas without any PAMAM or with PAMAM G1.5, composite films could not be formed [14]. Recently, PAMAM with different termini were used to investigate the interaction between protein and hydroxyapatite $\left(\mathrm{Ca}_{5}\left(\mathrm{PO}_{4}\right)_{3} \mathrm{OH}, \mathrm{HAP}\right)[15,16]$ and the synthesis of nanocrystalline (nano)-HAP [17-19]. PAMAM with terminal groups of $-\mathrm{NHC}(\mathrm{O}) \mathrm{CH}_{3},-\mathrm{COOH}$, and $-\mathrm{NH}_{2}$ were used as probes to study the alternating bands of charge distribution of natural enamel HAP crystals [15]. Zhou et al. found that the morphology and size of HAP were affected differently by carboxylic-terminated PAMAM and by polyhydroxyterminated PAMAM under hydrothermal treatment due to the different nucleation sites and adsorption onto the crystal surface [18]. Another study conducted by Yan et al. showed a PAMAM concentration dependent size change of ellipsoid-like HAP crystals synthesized by the hydrothermal method in the presence of PAMAM G4.0 with amido groups [17]. The shape and size of the crystals were also associated with the generation of PAMAM dendrimers [17].

In this article, we describe the functionalization of G2.0 PAMAM dendrimers with glutamic acid (PAMAM-GM) and the effect of the resulting dendrimer on calcium phosphate growth in double diffusion systems of either gelatin or agarose at room and $\mathrm{pH}$ 7.4. The advantages of double diffusion systems are that they not only need very little test molecule but also the slow diffusion process more realistically mimics the unique mineralized tissue matrix environment compared with non-gel solution studies [20]. The influence of PAMAM-MG on the morphology and phase of $\mathrm{CaP}$ crystals formed was also studied in a one way diffusion system without gels 
to investigate the contribution of the gel to the results in the double diffusion systems.

\section{Experimental section}

Materials

Tris(hydroxymethyl) aminoethane (ultra pure) and sodium azide (99\%) were from AMRESCO. Gelatin (Type A, 300 Bloom) was from Sigma-Aldrich Co. and agarose powder was from Biowest Agarose. The cation-selective membrane $\left(\mathrm{CMV}^{\mathrm{TM}}\right)$ was from Asahi Glass Co. and the dialysis membrane (Spectro/por ${ }^{\circledR}$ ) was from Spectrum Laboratories, Inc. Other reagents were all from Beijing Chemical Reagents.

\section{Measurements}

${ }^{1} \mathrm{H}$ NMR spectra were recorded on a Varian Mercury $300 \mathrm{MHz}$ NMR spectrometer at room temperature using tetramethylsilane as an internal standard. For the observation of morphology and composition of crystals formed in gels, transmission electron microscopy (TEM) was performed on a Hitachi H-9000 NAR TEM, operated at $300 \mathrm{keV}$. The sample was air-dried before measurement. The dried precipitate was examined by X-ray diffraction (XRD) and thermogravimetric analysis (TGA). XRD patterns were obtained with a Rigaku D/max-2400 X-ray diffractometer from $3^{\circ}$ to $60^{\circ}$ at a rate of $4 \% \mathrm{~min}$, using $\mathrm{Cu}-\mathrm{K} \alpha$ radiation $(K=0.1541 \mathrm{~nm})$. The tube voltage was $40 \mathrm{kV}$ and the tube current was $100 \mathrm{~mA}$. TGA was performed on a TA Q600SDT TGA-DTA-DSC instrument at a heating rate of $20 \% \mathrm{~min}$ in a nitrogen atmosphere. For the one way diffusion system, the precipitates on cation-selective membranes were characterized by scanning electron microscopy (SEM, Quanta $200 \mathrm{FEG}$ ) at an acceleration voltage of $20 \mathrm{kV}$. To determine the $\mathrm{Ca} / \mathrm{P}$ ratio of these precipitates, inductively coupled plasma (ICP) were performed on a Profile ICP-AES (Leeman Labs) with power set at $1.1 \mathrm{~kW}$ at $20{ }^{\circ} \mathrm{C}$.

\section{Synthesis of PAMAM-MG}

\section{Synthesis of $M G$}

The preparation of benzyl-protected glutamic acid has been previously reported [21]. In brief, $28.5 \mathrm{~g}(0.291 \mathrm{~mol})$ maleic anhydride and $11.83 \mathrm{~g}$ (0.036 mol) $\mathrm{N}$-deprotected glutamic acid were dissolved in $180 \mathrm{~mL}$ chloroform. The mixture was stirred at room temperature for $2 \mathrm{~h}$. The product obtained after evaporating the solvent under a vacuum was purified by chromatography over silica using ethyl acetate as the eluant. The yield was $72 \%$.

The resulting product that weighed $11.07 \mathrm{~g}(0.026$ mol $)$ was mixed with $14.9 \mathrm{~mL}$ $(0.158 \mathrm{~mol})$ acetic anhydride and $1.2 \mathrm{~g}(0.015 \mathrm{~mol})$ sodium acetate. The mixture 
was stirred at $90^{\circ}$ for $1 \mathrm{~h}$, then poured into $100 \mathrm{~mL}$ ice water and continuously stirred for an additional $5 \mathrm{~h}$. The crude products were further purified by repeated chromatography over silica at least three times using ethyl acetate as the eluant. After vacuum drying, the targeting compound MG was collected with a yield of $65 \%$. The composition was verified by ${ }^{1} \mathrm{H} \mathrm{NMR}\left(\mathrm{CDCl}_{3}, 300 \mathrm{MHz}, \mathrm{ppm}\right)$ : $\delta=7.34-7.39\left(\mathrm{~s}, 10 \mathrm{H},-\mathrm{C}_{6} H_{5}\right), 6.70(\mathrm{~s}, 2 \mathrm{H},-\mathrm{CH}=\mathrm{CH}-), 5.09-5.16\left(-\mathrm{CH}_{2}-\mathrm{C}_{6} \mathrm{H}_{5}\right)$, 4.77-4.83 (m, 1H, $\left.-\mathrm{CHCH}_{2}\right), 2.36-2.63\left(\mathrm{~m}, 4 \mathrm{H},-\mathrm{CH}_{2} \mathrm{CH}_{2}-\right.$ ).

\section{Synthesis of PAMAM-MG}

To a chloroform solution (5 mL) of G2 PAMAM dendrimer (0.91 g, $0.279 \mathrm{mmol})$, MG (1.82 g, $4.471 \mathrm{mmol})$ in chloroform $(5 \mathrm{~mL})$ was added dropwise and stirred at room temperature for $24 \mathrm{~h}$. The solvent was then evaporated, and the solid was dissolved with 10/1 v/v chromatogram-grade ethanol and deionized water. A $6 \mathrm{~mL}$ chromatogram-grade ethanol solution of $0.6 \mathrm{~g} \mathrm{KOH}$ was added to the reaction mixture and stirred for another $4 \mathrm{~h}$ at room temperature. The PAMAM-MG was obtained after dialysis (molecular weight 2000 cut-off) for $24 \mathrm{~h}$ followed by freezedrying with a yield of $47 \%$. The composition was verified by ${ }^{1} \mathrm{H} \mathrm{NMR}\left(\mathrm{CDCl}_{3}\right.$, $300 \mathrm{MHz}, \mathrm{ppm}): \delta=4.46(16 \mathrm{H}, \mathrm{NCHCO}), 3.99-4.01\left(32 \mathrm{H}, \mathrm{COCH}_{2} \mathrm{CH}_{2} \mathrm{~N}\right)$, 3.50-3.55 (16H, $\left.\mathrm{NCH}_{2} \mathrm{CH}_{2} \mathrm{CO}\right), 2.12-2.67$ (56H, 28- $\left.\mathrm{CH}_{2}-\mathrm{N}\left(-\mathrm{CH}_{2}-\right)-\mathrm{CH}_{2}-\mathrm{CH}_{2}-\right)$, 1.74-1.89 (16- $\left.\mathrm{CHCH}_{2} \mathrm{CH}_{2} \mathrm{COOH}\right)$. The process of PAMAM-MG synthesis is shown in Scheme 1.

\section{Double diffusion experiment}

The formation and growth of calcium phosphate crystals in a gelatin gel was monitored using $0,0.2,0.5,1$, and $5 \mathrm{mg} / \mathrm{mL}$ PAMAM-MG in $0.05 \mathrm{M} \mathrm{pH} 7.4$ Tris buffer containing $0.02 \% \mathrm{NaN}_{3}$ to prevent bacterial growth and $0.15 \mathrm{M} \mathrm{KCl}$ as a background electrolyte. These PAMAM-MG-containing Tris-buffered solutions were then used to make $10 \%$ gelatin gels. Gelatin powder was dissolved in the different PAMAM-MG Tris solutions at $50^{\circ}$ and then cooled to room temperature $\left(25 \pm 2{ }^{\circ} \mathrm{C}\right)$. Diffusion experiments were carried out at room temperature. For $1 \%$ agarose gels, only two PAMAM-MG concentrations (0 and $5 \mathrm{mg} / \mathrm{mL}$ ) were used. Agarose gels were heated above $90^{\circ}$ and agitated until completely clear.

The gels were mounted on an apparatus that allowed the circulation of a Trisbuffered $0.1 \mathrm{M}$ calcium nitrate solution and a $0.1 \mathrm{M}$ phosphate solution (molar ratio: $\left.\left(\mathrm{NH}_{4}\right)_{2} \mathrm{HPO}_{4} / \mathrm{NH}_{4} \mathrm{H}_{2} \mathrm{PO}_{4}=1: 1\right)$, both of which contained $0.15 \mathrm{M} \mathrm{KCl}$ and $0.02 \% \mathrm{NaN}_{3}$, from 1.51 containers on opposite sides of the gel. The gels were sealed with dialysis membranes (MW: 5000) in $4 \mathrm{~cm}$ long glass tubes (diameter $=0.6 \mathrm{~cm}$ ). The dialysis membranes were used to prevent both loss of the gels and diffusion of macromolecules into the circulating solutions.

After 1 week, the precipitates that first appeared near the phosphate side were carefully harvested from the gel. The gels containing them were melted at $60{ }^{\circ} \mathrm{C}$ (for those in agarose gels, the temperature was above $90{ }^{\circ} \mathrm{C}$ ) and washed with deionized water. The precipitates were then centrifuged for $3 \mathrm{~min}$ and the supernatant was discarded. This process was repeated six times to remove excessive 


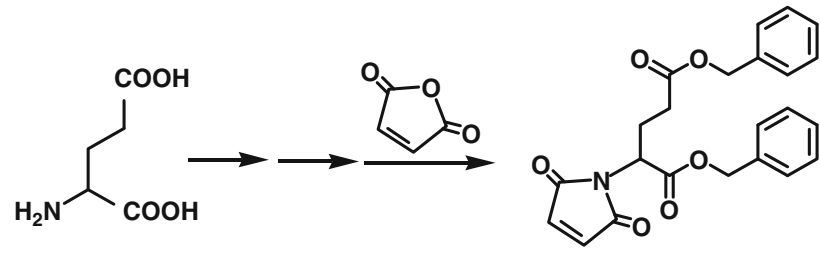

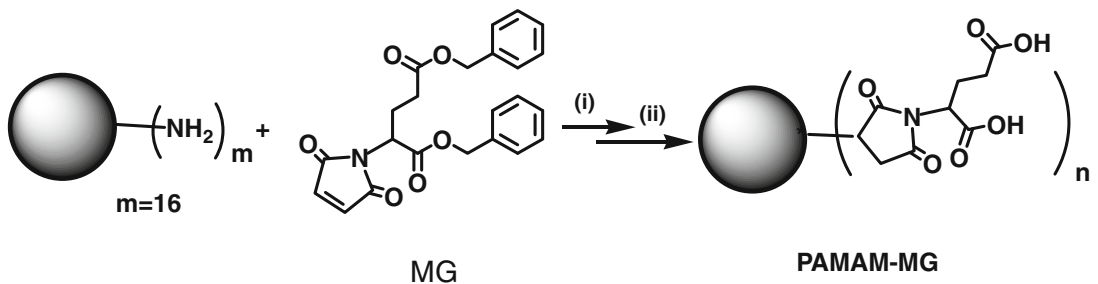

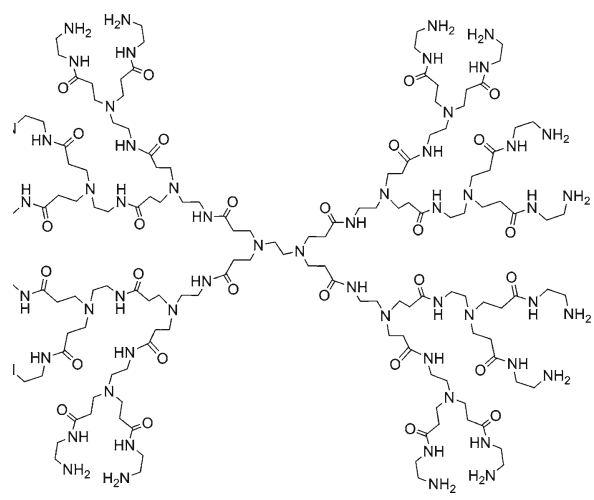

MAM G2.0

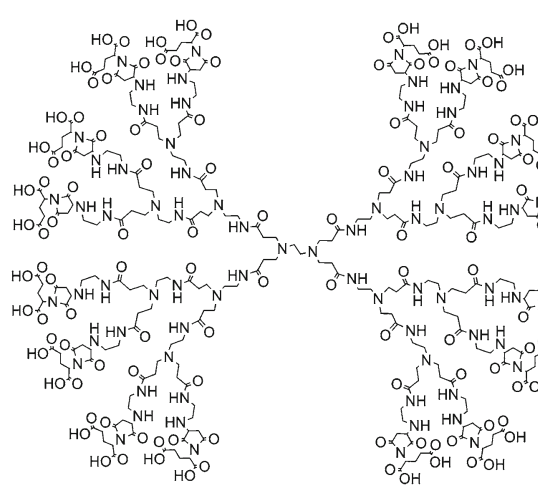

PAMAM-MG

Scheme 1 The synthesis of glutamic acid shelled PAMAM dendrimers

gel. A small amount of each sample was ultrasonically dispersed in ethanol. Finally, a drop of the ethanol solution was placed onto a carbon-film covered copper grid for TEM.

One way diffusion experiment on membranes

This experiment was designed to distinguish the effects of the gel from the effects of PAMAM-Mg and was similar to that described previously [22, 23]. Briefly, plastic bottles (40 mL volume) were filled with $30 \mathrm{mM}$ calcium nitrate solutions. They were sealed with cation-selective membranes for the control groups, and with both cation-selective membranes and dialysis membranes (MW: 5000) for the PAMAMMG groups. The space between the two membranes in the PAMAM-MG group contained $100 \mu \mathrm{L}$ of $5 \mathrm{mg} / \mathrm{mL}$ of PAMAM-MG solution. The bottles containing the calcium solutions were placed in a larger container $(500 \mathrm{~mL})$ containing $\mathrm{pH} 6.5$, $7.2 \mathrm{mM}$ phosphate solution (molar ratio: $\left(\mathrm{NH}_{4}\right)_{2} \mathrm{HPO}_{4} / \mathrm{NH}_{4} \mathrm{H}_{2} \mathrm{PO}_{4}=1: 1$ ). The 
Scheme 2 Illustration of the single diffusion system. Because only cations can penetrate the cation-selective membrane, precipitates form only on the phosphate side of the membrane

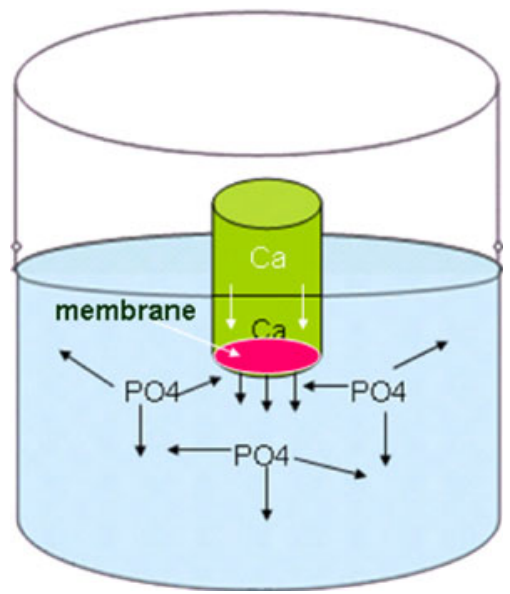

bottles were incubated at $37^{\circ} \mathrm{C}$ for 3 days. The experimental set-up is shown in Scheme 2.

\section{Results and discussion}

Crystal morphologies

The PAMAM dendrimers were synthesized and peripherally modified with glutamic acid as depicted in Scheme 1. The morphologies of calcium phosphate crystals formed were observed by TEM and SEM (Fig. 1a, b) with tape-like crystals formed both in gelatin and agarose gels in the presence of PAMAM-MG. The crystals had a
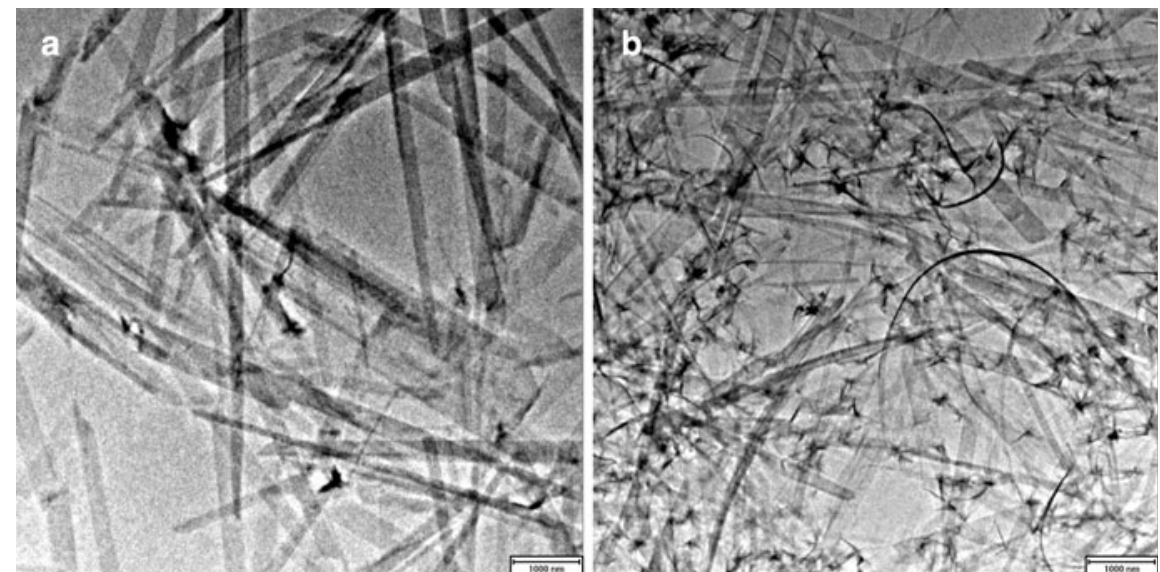

Fig. 1 TEM images of calcium phosphate crystals formed in gelatin (a) and agarose gels (b) with a $5 \mathrm{mg} / \mathrm{mL}$ concentration of PAMAM-MG 
width of about 200-250 nm and an almost uniform length, with both ends appearing pointed. However, the morphologies of the crystals grown without PAMAM-MG were quite different. The width of the calcium phosphate crystals was between 300 and $600 \mathrm{~nm}$ and the length varied from several hundreds nanometers to ten microns. With increasing concentration of PAMAM-MG, the crystals became narrower and more uniform in length. In addition, some of the crystals formed in agarose were bent, distinct from the straight crystals formed in gelatin gels. This size reduction in specific crystal dimensions had also been induced by natural and recombinant proteins. Iijima et al. found that both natural bovine and two recombinant murine amelogenins, which are rich in glutamic acid residues, reduced the thickness, width, and length of the OCP crystals formed in another system [24].

The morphology change may be due to the interaction of PAMAM-MG with $\mathrm{Ca}^{2+}$. One possibility is that PAMAM-MG serves as nucleation site, which leads to the binding of $\mathrm{Ca}^{2+}$ to the carboxylic acid groups on the PAMAM-MG surface. Such an interaction was reported by Khopade et al. [25] and Zhou et al. [18]. Zhou indicated that when - $\mathrm{COOH}$-terminated PAMAM dendrimers were mixed with $\mathrm{Ca}^{2+}$, the $\mathrm{O}-\mathrm{H}$ vibration shifted to a high frequency. Likewise, the absorbance peak of the carbonyl bond connected with the hydroxyl not only weakened greatly but also shifted to a lower frequency. Another possible interaction involves the interior dendritic branches, such as $\mathrm{N}-\mathrm{H}$, which are also able to coordinate with $\mathrm{Ca}^{2+}$ ions as confirmed by FT-IR [18]. The narrowing of the rectangular crystals was likely due to the absorbance of PAMAM on specific mineral surfaces.

To gain further insights into the morphology changes induced by PAMAM-MG, XRD was performed. XRD patterns (Fig. 2) of the samples from agarose gels without PAMAM-MG show the mineral phases of OCP and calcium-deficient HAP, and show only OCP in the presence of $5 \mathrm{mg} / \mathrm{mL}$ PAMAM-MG. The ICP analysis

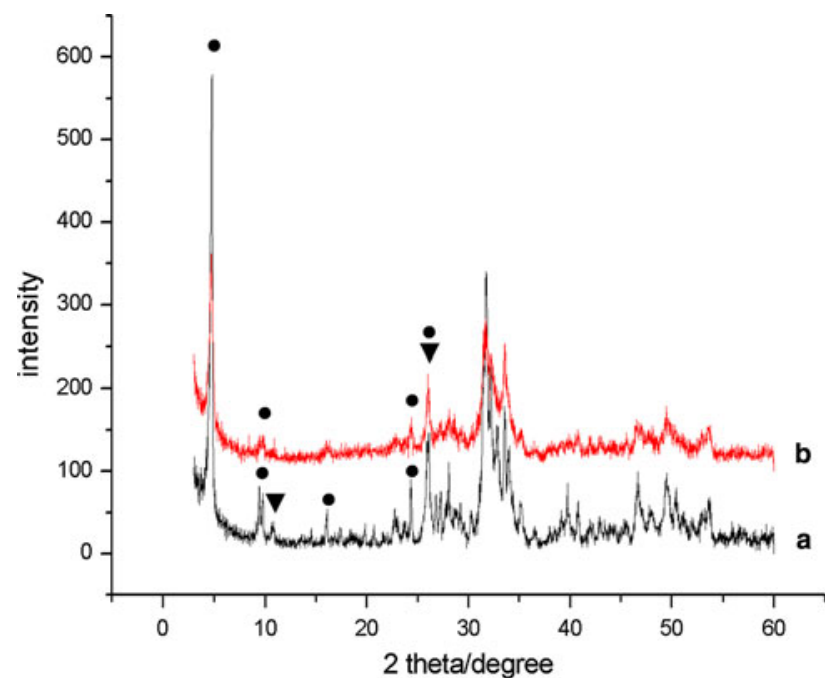

Fig. 2 XRD patterns of OCP crystals formed in agarose gels without PAMAM-MG (a) and with PAMAM-MG (b) at the concentration of $5 \mathrm{mg} / \mathrm{mL}$ (filled circle $\mathrm{OCP}$, filled inverted triangle $\mathrm{HAP}$ ) 
verified the phases formed: the $\mathrm{Ca} / \mathrm{P}$ ratio was calculated to be 1.51 for curve a and 1.36 for curve $b$ (the stoichiometric ratio is 1.33 and 1.67 for OCP and HAP, respectively). Interestingly, in our research, the solution $\mathrm{Ca} / \mathrm{P}$ ratio was 1 initially which would neither favor the formation of OCP nor HAP. However, many investigators have shown that the phase formed is not determined by the $\mathrm{Ca} / \mathrm{P}$ ratio, but by the environmental $\mathrm{pH}$. Hunter et al. [2] used $7.5 \mathrm{mM}$ calcium chloride and $7.5 \mathrm{mM}$ sodium phosphate in steady-state agarose gels to study the formation of HAP in the absence and presence of bone phosphoproteins at the $\mathrm{pH}$ of 7.4. Yoh et al. [26] found that DCPD formed at lower $\mathrm{pH}$, while OCP and HAP formed at higher $\mathrm{pH}$. Calcium phosphate $(\mathrm{Ca}-\mathrm{P})$ salts include: OCP, HAP, anhydrous dicalcium phosphate (DCPA; $\left.\mathrm{CaHPO}_{4}\right)$, dicalcium phosphate dihydrate or brushite (DCPD, $\left.\mathrm{CaHPO}_{4} \cdot 2 \mathrm{H}_{2} \mathrm{O}\right)$, beta-tricalcium phosphate or whitelockite $(\beta$-TCP, $\left.\mathrm{Ca}_{3}\left(\mathrm{PO}_{4}\right)_{2}\right)$ etc. OCP is believed by some to be a precursor phase of biological apatite in bone tissue, and it converts to HAP spontaneously. The unit cell of OCP is made up of apatitic layers and water layers, and the triclinic structure of OCP displays similarities with the hexagonal structure of HAP [27]. DCPA is the most stable $\mathrm{CaP}$ at a low $\mathrm{pH}$. Brushite is also considered to be a precursor or intermediate phase of HA during bone mineralization. However, in vitro by mixing a calcium hydroxide suspension and an orthophosphoric acid solution, the precipitation of brushite occurs after the initial precipitation of HA and through a very complex process [28]. $\beta$-TCP is a bioactive and biodegradable bone replacement material. It can also transform into HAP due to their structural similarity to the thermodynamically stable HAP [29]. However it does not usually form at physiologic temperatures. From curve b in Fig. 2, it can be seen that the 100 and 010 reflections of OCP at $2 \theta=4.7^{\circ}$ and $2 \theta=9.8^{\circ}$ are reduced, suggesting the growth of crystals along the $a$-axis (thickness) and $b$-axis (width) were decreased. In addition, the 100 reflection of HAP at $2 \theta=10.8^{\circ}$ almost disappeared in curve $b$, which might be due to PAMAM-MG hindering the formation of HAP. This result is similar to the effect of poly(aspartic acid) and poly(glutamic acid) on the OCP/HAP crystallization [30].

To better understand the effects of PAMAM-MG on the crystal growth of OCP, a cation-selective membrane was used to study crystal formation in solution without gelatin or agarose gels. These studies were performed at the physiologic temperature of $37{ }^{\circ} \mathrm{C}$. In this system at $\mathrm{pH}$ of 7.4 , only very short crystals formed on the membrane, thus we chose a $\mathrm{pH}$ of 6.5 at which OCP grew into long plates. Figure 3 shows the morphologies of the crystals from the systems with and without PAMAM-MG. As Fig. 3b shows, the crystals are much thinner and narrower compared with the crystals shown in Fig. 3a which were formed in the absence of PAMAM-MG. It is suggested that PAMAM-MG can be absorbed by both the 010 and 100 surfaces of OCP crystals, thus decreasing their width and thickness.

Poly-L-glutamate (PGLU) was reported to adsorb on the 100 surface of OCP because it is rich in carboxylate moieties. However, Furedimilhofer et al. found Poly-L-aspartate (PASP) adsorbed onto the 100 surface of OCP due to the peptides' $\beta$-sheet conformation, while PGLU and bone sialoprotein (BSP, rich in glutamic acid) had no effect on OCP crystal morphology because it does not adopt an ordered conformation [31]. Tsortos et al. considered that the special "train-loop" 

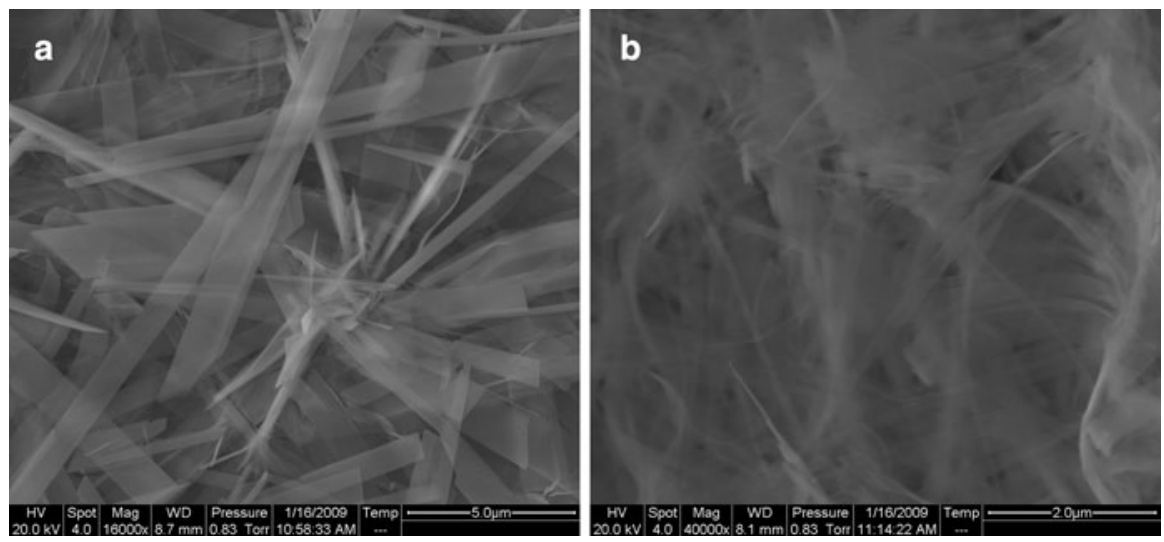

Fig. 3 SEM images of calcium phosphate crystals on cation-selective membranes without (a) and with (b) PAMAM-MG at the concentration of $5 \mathrm{mg} / \mathrm{mL}$. The $\mathrm{pH}$ of both experiments was 6.5

configuration of the coiled polymers on the surface of apatite crystals accounted for the crystal adsorption data, although polymers in the solution were flexible randomcoiled structures [32]. In contrast to linear polymers, PAMAM-MG has a unique shape and highly functionalized terminii. Thus, it may be the functionalized terminii that account for the adsorption onto crystal surfaces. Although it was reported that PAMAM could self-assemble due to the amphiphilic effect [33], PAMAM-MG does not show this behavior because the core and terminii are both hydrophilic. As a result, PAMAM-MG is not likely to adopt a self-assembled conformation to adsorb onto crystals surfaces.

The addition reaction between PAMAM and modified glutamic acid is not $100 \%$ complete, which results in variable graft ratios. In this study, the average graft ratio was $72 \%$. The terminii of $-\mathrm{COOH}$ and $-\mathrm{NH}_{2}$ at $\mathrm{pH} 7.4$ are negatively and positively charged, respectively [15]. The 100 and 010 surface of OCP are mostly positive and negative, respectively, according to the structure of OCP [34]. Therefore, charge attraction is most likely to play a very important role in the adsorption process.

The effects of gelatin gels on calcium phosphate crystallization

It has been suggested that gelatin might act as a nucleator or be absorbed onto crystal surfaces where it could regulate crystal growth [35]. Gelatin (denatured collagen) has a molecular weight of $\sim 300,000 \mathrm{Da}$, while PAMAM-MG's molecular weight is about 9,000 Da. From the TGA curves (Fig. 4) of mineral formed in the gelatin matrix, it can be seen that weight loss of these powders increases with increased PAMAM-MG concentration, except for the $0.2 \mathrm{mg} / \mathrm{mL}$ concentration. Similar curves are presented for a $(0 \mathrm{mg} / \mathrm{mL}), \mathrm{b}(0.2 \mathrm{mg} / \mathrm{mL}), \mathrm{c}(0.5 \mathrm{mg} / \mathrm{mL})$, and $\mathrm{d}(1 \mathrm{mg} / \mathrm{mL})$ with a weight loss of $25,24,27$, and $31 \%$ respectively. Curve e $(5 \mathrm{mg} / \mathrm{mL})$ shows the powder's approximate $45 \%$ weight loss. The weight loss of e is almost $20 \%$ more than that in the absence of PAMAM-MG (curve a). 


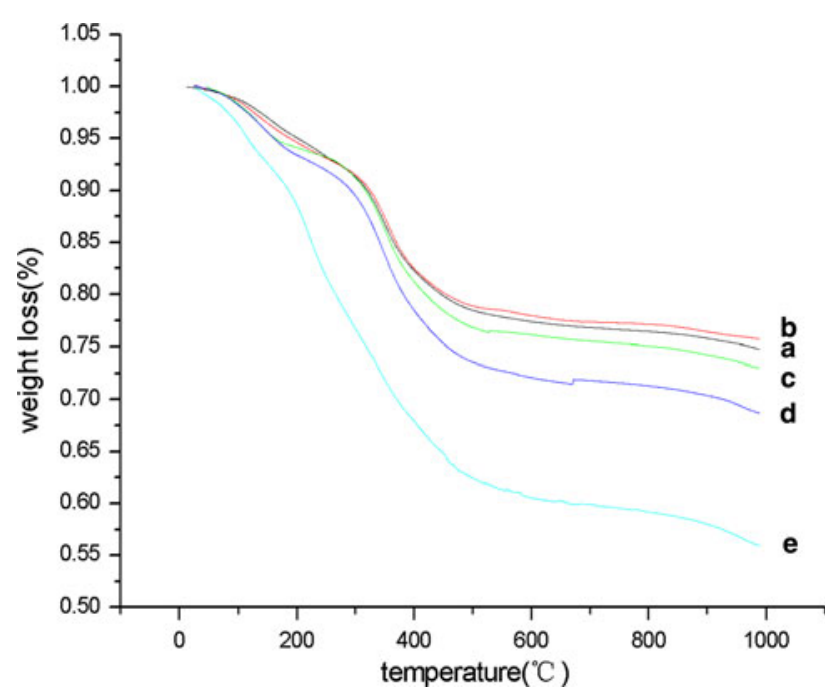

Fig. 4 TGA curves for precipitates formed in gelatin: a without PAMAM-MG, b $0.2 \mathrm{mg} / \mathrm{mL}$ PAMAM$\mathrm{MG}$, c $0.5 \mathrm{mg} / \mathrm{mL}$ PAMAM-MG, d $1 \mathrm{mg} / \mathrm{mL}$ PAMAM-MG, and e $5 \mathrm{mg} / \mathrm{mL}$ PAMAM-MG

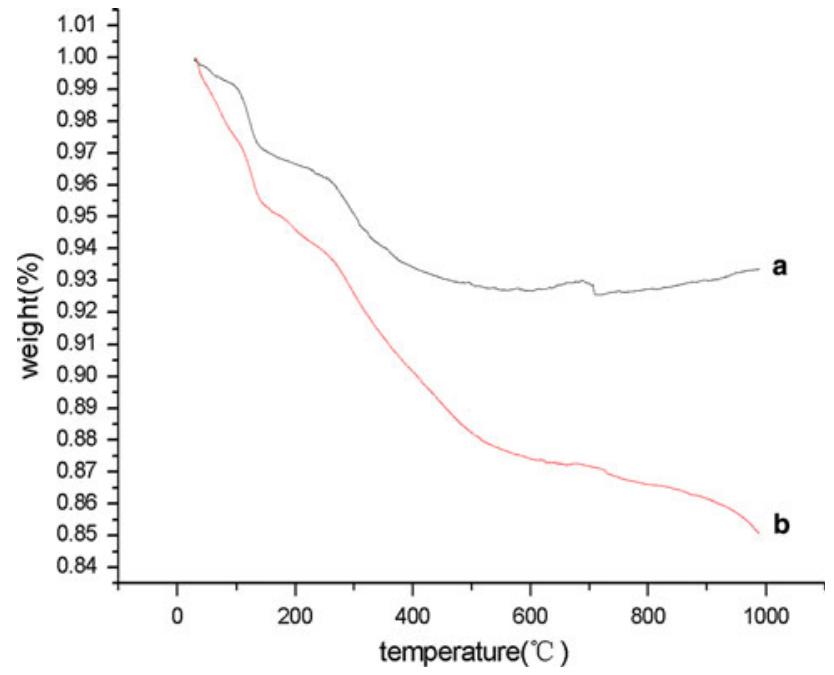

Fig. 5 TGA curves for precipitates formed in agarose: a without PAMAM-MG, b with $5 \mathrm{mg} / \mathrm{mL}$ PAMAM-MG

It is not likely that PAMAM-MG and the gelatin molecules simply competed with each other for binding sites on minerals. If this were the case, then weight loss would decrease with the increased PAMAM-MG concentration because of the relative difference in the amount of PAMAM-MG present. It is also unlikely the increased weight loss could be ascribed to additional bonding of PAMAM-MG to the crystal surface because only a small amount of weight loss (about $8 \%$ ) occurred with $5 \mathrm{mg} / \mathrm{mL}$ PAMAM-MG in agarose (Fig. 5). It is possible that PAMAM-MG 
and the gelatin molecules competed for binding sites and, at the same time, when PAMAM-MG concentration increased in gelatin gels, more and more gelatin molecules were associated with the mineral crystals due to bonding of gelatin to the PAMAM-MG molecules. This is illustrated in Scheme 3. We do not know the mechanism behind gelatin molecules' binding to PAMAM-MG, but collagen associates with anionic matrix proteins in tissues [36, 37] and by analogy gelatin may associate with PAMAM-MG. With increasing organic material contained in the powders, mineral formed in gelatin gels turned from OCP and apatite to amorphous $\mathrm{CaP}$ salts, a change confirmed by XRD diffraction (Fig. 6). The XRD patterns for all samples in Fig. 6 show an apatite and OCP phase with low crystallinity, except for the sample of $5 \mathrm{mg} / \mathrm{mL}$ whose pattern indicates that it is an amorphous $\mathrm{CaP}$. The background at all concentrations may suggest that ACP is present to some extent in
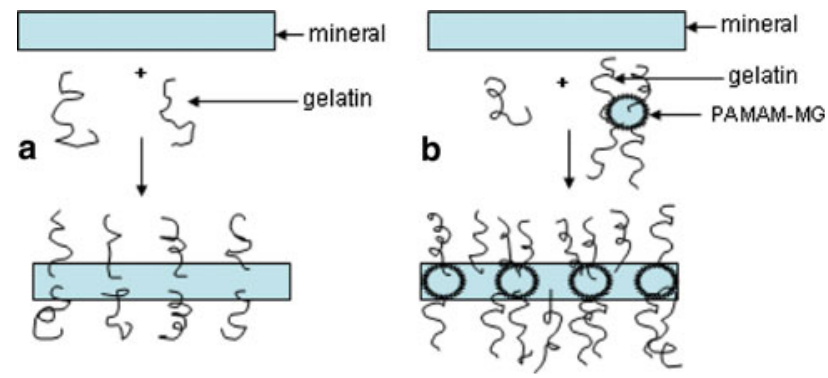

Scheme 3 Schematic illustrations of gelatin molecules' bonding to CaP crystals without (a) and with PAMAM-MG (b). By virtue of the affinity of PAMAM-MG for gelatin molecules, the gelatin contained increased with the increase in PAMAM-MG concentration

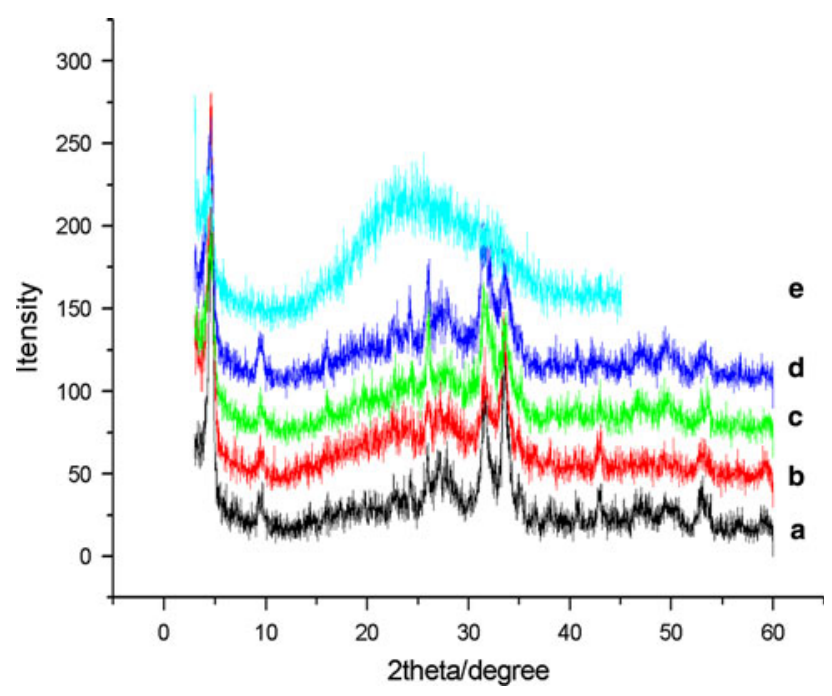

Fig. 6 XRD pattern for precipitates formed in gelatin: a without PAMAM-MG, b $0.2 \mathrm{mg} / \mathrm{mL}$ PAMAMMG, c $0.5 \mathrm{mg} / \mathrm{mL}$ PAMAM-MG, d $1 \mathrm{mg} / \mathrm{mL}$ PAMAM-MG, and e $5 \mathrm{mg} / \mathrm{mL}$ PAMAM-MG 
each preparation. A peak at two theta degrees of $4.7^{\circ}$ indicates the presence of OCP. The ICP results from curve a to e are $1.49,1.43,1.38,1.36$, and 1.55 , respectively. This may indicate that with the addition of PAMAM-MG, OCP is increasingly blocked from hydrolysis, some ACP is present in all cases, but at high PAMAMMG the ACP and OCP cannot convert to HA, and ACP becomes the only product minerals formed in agarose gels, however, had relatively high crystallinity due to the lesser amount of organic material contained. As far as we know, agarose is inert when used as a matrix gel in a double diffusion system.

\section{Conclusions}

In summary, glutamic acid shelled PAMAM dendrimers were synthesized, and the dendrimer found to interact with both OCP and apatite. This study suggests that PAMAM-MG may adsorb on OCP and on HAP's 100 and 010 surfaces, leading to decreased width and thickness. The data also suggests that PAMAM-MG may have an affinity for gelatin gels. The mechanism of PAMAM-MG's adsorption on crystals revealed by this study may cast some light on controlling crystals' dimensions using termini with different $-\mathrm{COOH} /-\mathrm{NH}_{2}$ ratios. The affinity for gelatin may be used to control the organic containing in the $\mathrm{CaP}$-gelatin composite.

Acknowledgments The authors thank Dr. Adele Boskey for her professional review and communications. We also acknowledge the financial support of Doctoral Fund of Ministry of Education of China (no. 20070001726) and National Natural Science Foundation of China (no. 30572063 and no. 30600717).

Open Access This article is distributed under the terms of the Creative Commons Attribution Noncommercial License which permits any noncommercial use, distribution, and reproduction in any medium, provided the original author(s) and source are credited.

\section{References}

1. Boskey AL, Maresca M, Appel J (1989) The effects of noncollagenous matrix proteins on hydroxyapatite formation and proliferation in a collagen gel system. Connect Tissue Res 21:501

2. Hunter GK, Kyle CL, Goldberg HA (1994) Modulation of crystal-formation by bone phosphoproteins - structural specificity of the osteopontin-mediated inhibition of hydroxyapatite formation. Biochem J 300:723

3. Sims SD, Didymus JM, Mann S (1995) Habit modification in synthetic-crystals of aragonite and vaterite. Chem Commun 10:1031

4. Gower LA, Tirrell DA (1998) Calcium carbonate films and helices grown in solutions of poly(aspartate). J Cryst Growth 191:153

5. Levi Y, Albeck S, Brack A, Weiner S, Addadi L (1998) Control over aragonite crystal nucleation and growth: an in vitro study of biomineralization. Chem- Eur J 4:389

6. Zhang HG, Zhu QS, Wang Y (2005) Morphologically controlled synthesis of hydroxyapatite with partial substitution of fluorine. Chem Mater 17:5824

7. Eiden-Assmann S, Viertelhaus M, Heiss A, Hoetzer KA, Felsche JJ (2002) The influence of amino acids on the biomineralization of hydroxyapatite in gelatin. Inorg Biochem 91:481

8. Naka K, Tanaka Y, Chujo Y, Ito Y (1999) The effect of an anionic starburst dendrimer on the crystallization of $\mathrm{CaCO}_{3}$ in aqueous solution. Chem Commun 19:1931 
9. Zhang F, Yang SP, Chen HM, Wang ZH, Yu XB (2004) The effect of an anionic starburst dendrimer on the crystallization of $\mathrm{BaWO}_{4}$ under hydrothermal reaction conditions. J Cryst Growth 267:569

10. Tomalia DA, Naylor AM, Goddard WA (1990) Starburst dendrimers-molecular-level control of size, shape, surface-chemistry, topology and flexibility from atoms to macroscopic matter. Angew Chem Int Ed 29:138

11. Ottaviani MF, Bossmann S, Turro NJ, Tomalia DA (1994) Characterization of starburst dendrimers by the EPR technique. 1 Copper-complexes in water solution. J Am Chem Soc 116:661

12. Naka K, Tanaka Y, Chujo Y (2002) Effect of anionic starburst dendrimers on the crystallization of $\mathrm{CaCO}_{3}$ in aqueous solution: size control of spherical vaterite particles. Langmuir 18:3655

13. Naka K, Chujo Y (2003) Effect of anionic dendrimers on the crystallization of calcium carbonate in aqueous solution. Chimie 6:1193

14. Tanaka Y, Nemoto T, Naka K, Chujo Y (2000) Preparation of $\mathrm{CaCO}_{3}$ /polymer composite films via interaction of anionic starburst dendrimer with poly(ethylenimine). Polym Bull 45:447

15. Chen H, Holl MB, Orr BG, Majoros I, Clarkson BH (2003) Interaction of dendrimers (artificial proteins) with biological hydroxyapatite crystals. J Dent Res 82:443

16. Chen HF, Chen YQ, Orr BG, Holl MM, Majoros I, Clarkson BH (2004) Nanoscale probing of the enamel nanorod surface using polyamidoamine dendrimers. Langmuir 20:4168

17. Yan SJ, Zhou ZH, Zhang F, Yang SP, Yang LZ, Yu XB (2006) Effect of anionic PAMAM with amido groups starburst dendrimers on the crystallization of $\mathrm{Ca}_{10}\left(\mathrm{PO}_{4}\right)_{6}(\mathrm{OH})_{2}$ by hydrothermal method. Mater Chem Phys 99:164

18. Zhou ZH, Zhou PL, Yang SP, Yu XB, Yang LZ (2007) Controllable synthesis of hydroxyapatite nanocrystals via a dendrimer-assisted hydrothermal process. Mater Res Bull 42:1611

19. Zhang F, Zhou ZH, Yang SP, Mao LH, Chen HM, Yu XB (2005) Hydrothermal synthesis of hydroxyapatite nanorods in the presence of anionic starburst dendrimer. Mater Lett 59:1422

20. Silverman L, Boskey AL (2004) Diffusion systems for evaluation of biomineralization. Calcified Tissue Int 75:494

21. Ji Y, Luo YF, Jia XR, Chen EQ, Huang Y, Ye C, Wang BB, Zhou QF, Wei Y (2005) A dendron based on natural amino acids: synthesis and behavior as an organogelator and lyotropic liquid crystal. Angew Chem Int Ed 44:6025

22. Iijima M, Du C, Abbott C, Doi Y, Moradian-Oldak J (2006) Control of apatite crystal growth by the co-operative effect of a recombinant porcine amelogenin and fluoride. Eur J Oral Sci 114(Suppl 1):304

23. Iijima M, Moradian-Oldak J (2004) Control of octacalcium phosphate and apatite crystal growth by amelogenin matrices. J Mater Chem 14:2189

24. Iijima M, Moradian-Oldak J (2004) Interactions of amelogenins with octacalcium phosphate crystal faces are dose dependent. Calcified Tissue Int 74:522

25. Khopade AJ, Khopade S, Jain NK (2002) Development of hemoglobin aquasomes from spherical hydroxyapatite cores precipitated in the presence of half-generation poly(amidoamine) dendrimer. Int J Pharm 241:145

26. Yoh R, Matsumoto T, Sasaki JI, Sohmura T (2008) Biomimetic fabrication of fibrin/apatite composite material. J Biomed Mater Res A 87A:222

27. Bigi A, Bracci B, Panzavolta S, Iliescu M, Plouet-Richard M, Werckmann J, Cam D (2004) Morphological and structural modifications of octacalcium phosphate induced by poly-L-aspartate. Cryst Growth Des 4:141

28. Ferreira A, Oliveira C, Rocha F (2003) The different phases in the precipitation of dicalcium phosphate dihydrate. J Cryst Growth 252:599

29. Rodriguez-Lugo V, Hernandez JS, Arellano-Jimenez MJ, Hernandez-Tejeda PH, Recillas-Gispert S (2005) Characterization of hydroxyapatite by electron microscopy. Microsc Microanal 11:516

30. Bigi A, Boanini E, Bracci B, Falini G, Rubini K (2003) Interaction of acidic poly-amino acids with octacalcium phosphate. J Inorg Biochem 95:291

31. Furedimilhofer H, Moradian-Oldak J, Weiner S, Veis A, Mintz KP, Addadi L (1994) Interactions of matrix proteins from mineralized tissues with octacalcium phosphate. Connect Tissue Res 30:251

32. Tsortos A, Nancollas GH (2002) The role of polycarboxylic acids in calcium phosphate mineralization. J Colloid Interface Sci 250:159

33. Wang BB, Zhang X, Jia XR, Li ZC, Ji Y, Yang L, Wei Y (2004) Fluorescence and aggregation behavior of poly(amidoamine) dendrimers peripherally modified with aromatic chromophores: the effect of dendritic architectures. J Am Chem Soc 126:15180 
34. Iijima M, Moriwaki Y, Takagi T, Moradian-Oldak J (2001) Effects of bovine amelogenins on the crystal morphology of octacalcium phosphate in a model system of tooth enamel formation. J Cryst Growth 222:615

35. Chen MF, Tan JJ, Lian YY, Liu DB (2008) Preparation of Gelatin coated hydroxyapatite nanorods and the stability of its aqueous colloidal. Appl Surf Sci 254:2730

36. Chen Y, Bal BS, Gorski JP (1992) Calcium and collagen binding-proteins of osteopontin, bone sialoprotein, and bone acidic glycoprotein-75 from bone. J Biol Chem 267:24871

37. Matsuura T, Duarte WR, Cheng H, Uzawa K, Yamauchi M (2001) Differential expression of decorin and biglycan genes during mouse tooth development. Matrix Biol 20:367 